a věnované 15 . výročí zahájení výuky ukrajinštiny jako studijního oboru na Filozofické fakultě Masarykovy univerzity. Brno: Masarykova univerzita, 2009. ISBN 978-80-210-4964-2.

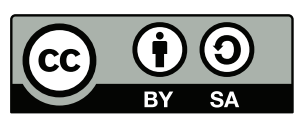

Toto dílo Ize užít v souladu s licenčními podmínkami Creative Commons BY-SA 4.0 International (<https:// creativecommons.org/licenses/by-sa/4.0/legalcode>). Uvedené se nevztahuje na díla či prvky (např. obrazovou či fotografickou dokumentaci), které jsou v díle užity na základě smluvní licence nebo výjimky či omezení príslušných práv.

https://doi.org/10.5817/OS2019-4-9

\title{
О дискурсе, двух основных школах дискурс-анализа и возможностях дискурс-анализа в новом учебнике Н. Цингеровой и К. Мотыковой Úvod do diskurznej analýzy
}

CINGEROVÁ, N. - MOTYKOVÁ, K.: Úvod do diskurznej analýzy. Bratislava: Univerzita Komenského v Bratislave, 2017. 174 s. ISBN 978-80-223-4385-5.

Термин дискурс обычно относится к использованию языка в социальном взаимодействии и, в наиболее общем смысле, охватывает не только сам текст, но в более широком смысле его участники включаются в непосредственный контекст. Как правило, дискурс связан с определённой группой пользователей (в отдельных случаях с отдельным лицом), имеет отношение к конкретной социальной или коммуникационной ситуации (или общественному учреждению) и обычно имеет дело с определённой темой или набором тем.

Существует ряд пересекающихся концепций дискурса, базирующихся на различных теоретических основах, и формулирование его однозначного определения ещё более осложняется тем фактом, что эта концепция связывает язык, общение, взаимодействие, культурный, исторический и социальный контекст и т.д.

В представленном вниманию студентам разных сфер гуманитарных и общественных наук, а также более широкой научной общественности вузовском учебнике Úvod do diskurznej analýzy, написанном в рамках грантового проекта № FGo7/2015, авторы Нина Цингерова - кандидат филологических наук, старший преподаватель кафедры русистики и восточноевропейских исследований Философского факультета Университета им. Коменского в Братиславе и Катарина Мотыкова - кандидат филологических наук, старший 
преподаватель кафедры германистики, нидерландистики и скандинавистики одноимённого факультета - рассматривают проблематику дискурс-анализа на основе двух школ: эссекской школь дискурс-анализа (Э. Лаклау и Ш. Муфф, Я. Торфинг, Я. Ставракакис, Д. Ховард и О. Марчарт) и критического дискурс-анализа (Т. А. ван Дейк, Н. Феркло, Т. ван Леувен, Р. Водак, С. Егерь). В рамках первой школы, соблюдая политико-философский подход, затрагивается, прежде всего, проблематика понимания структуры дискурса, взаимоотношения внутри него и внутренней организации дискурса. Вторая школа, используя дискурсивно-лингвистический подход, позволяет интерпретировать дискурс, т. е. делает доступным анализ единиц, произведённых дискурсом.

Как в ведении утверждают авторы, «тема анализа дискурса не является в словацком контексте совсем новой» ${ }^{1}$ и приводят ряд работ и фамилий исследователей, занимающихся в словацком языкознании, прежде всего, критическим дискурс-анализом ${ }^{2}$.

Главной целью Н. Цингеровой и К. Мотыковой было «создать и предложить подходящий учебный материал не только для студентов филологических и ареальных исследований, главным образом лингвистики, переводоведения, но и социологии, истории, политологии и философии» ${ }^{3}$. Авторы предполагают, что учебник будет полезен не только на семинарах, посвящённых межкультурности, теоретическим и практическим аспектам лингвистики, но также и для исследования средств массовой информации, анализа текста, истории и реалий, при написании курсовых работ, предметом исследования которых являются формы языкового и неязыкового поведения, для имагологического анализа и т. п.

В центре внимания рецензируемого нами учебника являются монологические медиатексты. Диалогические тексты или устные взаимодействия в неформальных условиях в рамках предлагаемых авторами методологических приёмов и примеров не приводятся, так как Н. Цингерова и К. Мотыкова исходят «из собственного педагогического опыта - из опроса студентов, у которых мы работали в качестве консультантов при написании курсовых работ, а также из концепции курсов, в рамках которых уделяем внимание данной проблематике» ${ }^{4}$.

Представленный учебник Н. Цингеровой и К. Мотыковой отличается чёткостью композиции и продуманной структурой. Он состоит из семи глав,

1 CINGEROVÁ, N. - MOTYKOVÁ, K.: Úvod do diskurznej analýzy. Bratislava: Univerzita Komenského v Bratislave, 2017, c. 7.

2 Там же, с. 7-8

3 Там же, с. 9

4 Там же, с. 9 
представляющих собой объяснение теоретических основ, основные определения существенных понятий и примеры из средств массовой информации с коротким толкованием. Составной частью учебника также является предисловие и список используемой литературы. Положительной оценки заслуживают приведённые авторами в конце каждой главы учебника задания с целью мотивирования преподавателей и учащихся для работы с другими текстами. Кроме шестой главы даётся и список рекомендуемой литературы.

В первой главе (Úvod do problematiky) Н. Цингерова и К. Мотыкова знакомят читателя с проблематикой социального конструкционизма, основным вектором, разделяющим взгляды большинства теоретиков и аналитиков дискурса. Социальный конструктивизм - это социологическая теория познания, развитая Питером Бергером и Томасом Лукманом в их книге «Социальное конструирование реальности: Трактат по социологии знания» ${ }^{5}$, изданной также в переводе на чешский язык ${ }^{6}$. В подразделе 1.2 (Základné znaky sociálneho konštrukcionizmu) Н.Цингерова и К. Мотыкова также приводят обобщённые основные черты социального конструкционизма согласно Вивиан Бурр. В подразделе 1.3 (С̌o vlastne konštruujeme?) авторы анализируют объект исследования по духу социального конструктивизма, не отрицающего существование реального мира, что согласно авторам «бывает часто ядром критики данной теоретической рамки» ${ }^{7}$.

Во второй главе (Jazyková prax, vedenie a тос) Н. Цингерова и К. Мотыкова рассматривают следующее центральное понятие современных гуманитарных и общественных наук - дискурс. В связи с инфляцией этого понятия, определённой десемантизацией и неоднозначностью авторы объясняют, что «именно от определения понятия развивается потенциал дискурсивной точки зрения на общественную и научную проблематику», причём продолжают, что в трактовке этого понятия скрывается «ответ на вопрос, до какой степени и в каких взаимосвязях можно опереться на анализ дискурса при исследовании общественных и политических феноменов» ${ }^{8}$. В связи с этим Н.Цингерова и К. Мотыкова в данном подразделе выделяют две условные группы восприятия и присвоения понятия дискурс. В первую, филологически и лингвистически/социолингвистически закреплённую группу, в связи со

5 BERGER, P. L. - LUCKMANN, Th.: The Social Construction of Reality: a Treatise in the Sociology of Knowledge. London: Penguin Books, 1966.

6 BERGER, P. L. - LUCKMANN, Th.: Sociální konstrukce reality: Pojednání o sociologii vědění. Brno: CDK, 1999.

7 CINGEROVÁ, N. - MOTYKOVÁ, K.: Úvod do diskurznej analýzy. Bratislava: Univerzita Komenského v Bratislave, 2017, c. 21.

8 Там же, с. 31. 
структурой инструментария анализа дискурса, упоминают русский формализм, пражский стуктурализм, произведение русского фольклориста и филолога Владимира Яковлевича Проппа, а также лингвистику текста (Р. де Богранд, В. У. Дресслер, Т. А. ван Дейк). В рамках постструктуралистического понимания, во вторую условную группу авторы включают представителей так наз. Әссекской школь дискурсивного анализа (Э. Лаклау, Ш. Муфф, Я. Торфинг, Я. Ставракакис, Д. Ховард, О. Марчарт).

В подразделе 2.2 (Diskurz podla Michela Foucaulta) Н. Цингерова и К. Мотыкова уделяют внимание дискурсивной теории в книге М. Фуко ${ }^{9}$, изданной также в переводе на чешский язык ${ }^{10}$. М. Фуко в данной книге определяет дискурс как «группу высказываний, если они принадлежат к тождественной дискурсивной формации [...]» и «[...] он образован ограниченным количеством высказываний, для которых может быть определён набор условий их существования» ${ }^{11}$, причём дискурс не воспринимается как совокупность знаков, а, скорее всего, как «совокупность практик, систематически образующих объекты, о которых говорится», т.е. как конструирующую силу ${ }^{12}$. Оцениваем факт, что для более глубокого понимания понятия дискурс согласно теории Фуко, авторы в следующих пяти подразделах приводят трактовки и других вспомогательных понятий, используемых Фуко при определении понятия дискурс, таких как высказывание, правила формирования, дискурсивная формация, практики, власть и правда.

В третьей главе (Diskurz E. Laclaua a Ch. Mouffovej) речь идёт о теории дискурса Э. Лаклауа и Ш. Муфф, возникшей согласно Н. Цингеровой и К. Мотыковой «как «побочный продукт» политологического исследования, основу которого составляла переоценка «классических» марксистских понятий и постулатов» ${ }^{13}$. Э. Лаклау и Ш. Муфф - представители Эссекской школы дискурс-анализа понимают дискурс как «всеобъемлющий» и отказываются от разграничения между дискурсивными (в большей мере понимаемыми как «языковыми») и недискурсивными полями деятельности. Для дискурсивных и недискурсивных практик употребляют одно понятие - артикуляционная практика (артикуляция) и структурный тоталитаризм, являющихся результатом артикуляционной практики, называя дискурсом. В подразделе 3.2 (Diskurz a pole diskurzivity) авторы освещают проблематику структурации «тоталитаризма»

9 FOUCAULT, M.: L'archéologie du savoir. Paris: Gallimard, 1969.

10 FOUCAULT, M.: Archeologie vědění. Praha: Hermann \& synové, 2002.

11 Там же, с. 180.

12 Там же, с. 78-79.

13 CINGEROVÁ, N. - MOTYKOVÁ, K.: Úvod do diskurznej analýzy. Bratislava: Univerzita Komenského v Bratislave, 2017, c. 57 . 
и внутренней логики функционирования дискурса, акцентируя неустойчивость поля дискурсивности без крепко закреплённых идентичностей знаков, которые Э. Лаклау и Ш. Муфф называют элементами и приходят к выводу, что «каждый дискурс стремится захватить поле дискурсивности, назначить относительные позиции знаков и сконструировать центр ${ }^{14}$. Э. Лаклау и Ш. Муфф центр называют «узловая точка (nodal point)» ${ }^{15}$ и более подробную трактовку этого термина с примером Н. Цингерова и К. Мотыкова приводят в подразделе 3.5 (Prázdne označujúce a uzlový bod). В следующих двух подразделах авторы отмечают проблему границ дискурса, переоценки традиционной концептуализации понятия антагонизм, а также отношения дислокаций и антагонизма.

Основная проблема четвёртой главы - это критический дискурс-анализ, значительно отличающийся от концепта дискурса согласно Эссекской школы дискурс-анализа в том, что, как утверждают Н. Цингерова и К. Мотыкова «на первый план выступает деление общественной практики на дискурсивные и недискурсивные поля деятельности» и воспринимают его «через призму языка соответствующего социального действия» ${ }^{16}$. В подразделе 4.2 (Základné tézy $(D A)$ авторы приводят основные тезисы критического дискурс-анализа, эксплицитно сформулированные дискурсивными аналитиками Дуисбурского института для исследования языка и общества в 80-х годах прошлого столетия, определяя направление анализов текстов критических дискурсивных аналитиков на миграционный дискурс, дискурс о расизме, ксенофобии и др. В подразделе 4.3 (Úrovne analýzy) Н.Цингерова и К. Мотыкова в связи с двумя типами социальной практики, двумя разными областями, требующими разных подходов, говорят о трёх уровнях (текстуальная, социальная практика, дискурсивная практика) анализа яркого представителя критического дискурс-анализа Н. Феркло ${ }^{17}$, сопоставляя их с тремя уровнями (интратекстовый, уровень соучастников и транстекстовый уровень) двух представителей так наз. лингвистического дискурс-анализа - Й.Шпицмюллера и И.Г.Варнке. Их понимание, однако, согласно авторам рецензируемого учебника, является «более монодисциплинарное и текстоцентрическое» ${ }^{18}$. Т. Нир подчёркивает, что «не все тексты можно анализировать на всех приведённых уровнях, так как

14 LACLAU, E. - MOUFFE, Ch.: Hegemonie a socialistická strategie: za radikálně demokratickou politiku. Praha: Karolinum, 2014, c. 138.

15 LACLAU, E.: On Populist Reason. London, New York: Verso, 2007, c. 96.

16 CINGEROVÁ, N. - MOTYKOVÁ, K.: Úvod do diskurznej analýzy. Bratislava: Univerzita Komenského v Bratislave, 2017, c. 75 .

17 Ср. схему трёхдименсиональной модели Н. Феркло: CINGEROVÁ, N. - MOTYKOVÁ, K.: Úvod do diskurznej analýzy. Bratislava: Univerzita Komenského v Bratislave, 2017, c. 80.

18 Там же, c. 81. 
не всегда идёт речь, например, о мультимодальном тексте, содержащем также картинный материал» и продолжает, что «подробный и постепенный разбор всех уровней текстового корпуса согласно Й. Шпицмюллеру и И. Г. Варнке не является желательным» ${ }^{19}$. Они, скорее всего, предлагают методологическую рамку дискурсивной лингвистики, обозначаемую как «методологическую интеграционную модель, позволяющую лучше ориентироваться в дискурсе» ${ }^{20}$.

В подразделе 4.4 (Diskurz a diskurzy) авторы, рассматривая отношение между дискурсом и другими дискурсами согласно пониманию критического дискурс-анализа, приводят четыре причины ${ }^{21}$ для определения институциональной и коммуникативной рамки, в пределах которой перемещаются продюсеры и реципиенты дискурсов.

В подразделе 4.5 (Nástroje analýzy) Н. Цингерова и К. Мотыкова в рамках проблемно ориентированного подхода к дискурс-анализу выбирают сжатую модель, рекомендуемую в пределах дискурсивно исторического подхода представителей так наз. Венской школь критического дискурс-анализа (Р. Водак и М. Райсигл), подходящей, главным образом, для «анализа специфических дискурсов расистскими, антисемитскими, националистическими и этническими элементами» ${ }^{22}$. В связи с данной моделью авторы приводят три конкретные размерности, причём в третьей особо выделяют пять основных вопросов для выделения существенных дискурсивных стратегий: номинационных ${ }^{23}$, предсказуемых $^{24}$, аргументационных ${ }^{25}$. Положительно оцениваем приведение ${ }^{26}$ детального конкретного хода для дискурсивного анализа согласно С. Егеру и М. Егеровой - представителей Дуисбурской школы дискурс-анализа, а также в рамках заданий после главы включение конкретного примера текста для анализа, опубликованного в словацкой газете $\mathrm{SME}^{27}$.

В пятой главе (Kriticko-diskurzná perspektíva Teuna A.van Dijka) авторы рассматривают подход Т.А.ван Дейка к критическому дискурс-анализу,

19 NIEHR, Th.: Einführung in the linguistishe Diskuranalyse. Darmstadt: WBG, 2014, c. 68.

20 SPITZMÜLLER, J. - WARNKE, I. H.: Diskurslinguistik. Eine Einführung in Theorien und Methoden der transtextuellen Sprachanalyse. Berlin-Boston: De Gruyter, 2011, c. 199.

21 CINGEROVÁ, N. - MOTYKOVÁ, K.: Úvod do diskurznej analýzy. Bratislava: Univerzita Komenského v Bratislave, 2017, c. 86-87.

22 REISIGL, M. - WODAK, R.: Discourse and Discrimination: Rhetorics of Racism and Antisemitism. London; New York: Routhledge, 2001, c. 44 .

23 CINGEROVÁ, N. - MOTYKOVÁ, K.: Úvod do diskurznej analýzy. Bratislava: Univerzita Komenského v Bratislave, 2017, c. 89 .

24 Там же, с. 90-93.

25 Там же, с. 93-98.

26 Там же, с. 99-100.

27 Там же, с. 101-103. 
подчёркивающего мультидисциплинарный характер такого анализа с уточнением его названия вместо Critical Discourse Analysis (CDA) обозначение Critical Discourse Studies (CDS). Ван Дейк это аргументирует тем, что «речь идёт, скорее всего, о научной дисциплине, располагающей многими типами анализа дискурса» ${ }^{28}$. В подразделе 5.2 (Sociokognitívny prístup) речь идёт о социокогнитивном дискурс-анализе согласно Т. А. ван Дейку, которого в рамках данного анализа принципиально интересуют отношения между мыслью, дискурсивным взаимодействием и обществом. В своих работах ван Дейк обращает внимание на факт, что «когниция, дискурс и общество находятся во взаимных отношениях, которые являются очень сложными, взаимно влияют друг на друга, их отношение, таким образом, является двусторонним и, одновременно, многоуровневым и, одновременно, имеет когнитивную и социальную природу» ${ }^{29}$. В связи с анализом дискурса ван Дейк говорит о контекстовых моделях, являющихся «посредниками между дискурсивными и социальными структурами на всех уровнях дискурс-анализа» ${ }^{30}$. Самым важным вопросом для ван Дейка является отношение общественных структур к дискурсивным структурам, исходя при этом из того, что отношение общества и дискурса определяется посредством социальных соучастников и их мысли. На уровне социальной когниции ван Дейк занимается именно идеологиями, причём, в своём подходе к ним исходит из трёх основных элементов, таких как «социальные функции (social functions), когнитивные структуры (cognitive structures), демонстрация дискурса и его репродукция (discoursive expression and reproduction)» ${ }^{31}$. Также оцениваем факт, что для более тщательного понимания социокогнитивного подхода ван Дейка Н. Цингерова и К. Мотыкова на с. 113-115 приводят толкование некоторых избранных понятий.

Проблематика, посвященная коллективной символике согласно С. Егеру и М.Егеровой (взаимодействующие коллективные символы, культурные стереотипы, передающиеся и используемые коллективно, а также образность,

28 VAN DIJK, T. A.: Critical Discourse Studies: A Sociognitive Approach. In: WODAK, R. - MEYER, M. (eds): Methods of Critical Discourse Analysis. Second Edition. Los Angeles; London; New Delphi; Singapore; Washington DC: Sage Publications, 2010, c. 64 .

29 VAN DIJK, T. A.: Ideology: A Multidisciplinary Approach. London; Thousand Oaks; New Delphi: Sage Publications, 1998, c. 13 .

30 VAN DIJK, T. A.: Critical Discourse Studies: A Sociognitive Approach. In: WODAK, R. - MEYER, M. (eds): Methods of Critical Discourse Analysis. Second Edition. Los Angeles; London; New Delphi; Singapore; Washington DC: Sage Publications, 2010, c. 66.

31 GARRET, P. - BELL, A.: Media and Discourse: A Critical Overview. In: BELL, A. - GARRET, P. (eds): Approaches to Media Discourse. Oxford; Malden: Blackwell Publisher, 1998, c. 7 . 
клише, метафоры) ${ }^{32}$, освещается Н. Цингеровой и К. Мотыковой в шестой главе (Kolektívna symbolika). Систему коллективной символики в виде круга, разделяя его согласно С. Егеру и М. Егеровой горизонтально, вертикально и диагонально, границы которого выражают границы социальной системы, приводят Н. Цингерова и К. Мотыкова на с. 120, дополняя его последующим подробным комментарием $^{33}$ и конкретным примером ${ }^{34}$. В подзаголовке 6.2 (Kritériá kolektívneho výskumu) Н. Цингерова и К. Мотыкова характеризуют свойства коллективного символа, такие как семантическая вторичность, визуальная изображенность или иконичность, мотивированность, многозначность, синтагматическая экспансивность, аналогические отношения между означающим (сигнификантом) и означаемым (сигнификатом), дополняя трактовку конкретными примерами из электронных и бумажных источников.

В седьмой главе (Multimodálna analýza diskurzu) мы вполне согласны с мнением Н. Цингеровой и К. Мотыковой о необходимости «методологического обоснования исследования текстов, построенных при помощи разных семиотических источников (модов)» ${ }^{35}$. Речь идёт о мультимодальных текстах, причём, авторы по поводу данной проблематики констатируют, что «по сравнению с уже упоминаемыми подходами к анализу дискурса так наз. мультимодальный анализ дискурсов более скромно представлен в научной литературе» ${ }^{36}$.

В подразделе 7.1 (Špecifiká sociálnej semiotiky) авторы суммируют специфику социальной семиотики и в следующем подразделе Н. Цингерова и К. Мотыкова акцентируют использование так наз. коммутативного теста, разработанного пражским и копенгагенским лингвистическим кружком. На основе данного теста, основывающегося на трансформациях на парадигматическом и синтагматическом уровнях, авторы приводят в следующих подразделах пример анализа № 1 (обложка журнала Тýždeň) и № 2 (анализ мемориальной доски «ВЕРБА»), представляющих собой возможности мультимодального анализа дискурса в общих чертах. Радует факт, что возможности анализа мультимодальных текстов, а также частично возможности анализа памятников были также представлены на международных конференциях в Санкт-Петербурге, что свидетельствует о глубокой заинтересованности Н.Цингеровой в данной проблематике.

32 Cp.JÄGER, S. - JÄGER, M.: Deutungskämpfe. Theorie und Praxis Kritischer Diskursanalyse. Wiesbaden: VS-Verlag, 2007.

33 CINGEROVÁ, N. - MOTYKOVÁ, K.: Úvod do diskurznej analýzy. Bratislava: Univerzita Komenského v Bratislave, 2017, c. 120-121.

34 Там же, c. 122-123.

35 Там же, c. 140.

36 Там же, c. 140 
Таким образом, следуют отметить, что рецензируемый вузовский учебник Н. Цингеровой и К. Мотыковой отличается логичностью изложения, убедительностью аргументации при обосновании выдвигаемых положений и написан соответствующим научным и одновременно доступным языком. Рецензируемый учебник, безусловно, окажет позитивное влияние на дальнейшее исследование дискурса.

Этот качественный и профессионально написанный учебник, в целом, производит очень положительное впечатление, и поэтому заслуживает своего места и надлежащего внимания среди других публикаций, направленных на аналогичные вопросы.

В целом полагаю, что авторы проделали большую и серьёзную работу, и книга заслуживает самой высокой оценки.

Ян Галло

\section{Литература:}

BERGER, P. L. - LUCKMANN, Th.: Sociální konstrukce reality: Pojednání o sociologii vědění. Brno: CDK, 1999. ISBN 80-85959-46-1.

BERGER, P. L. - LUCKMANN, Th.: The Social Construction of Reality: a Treatise in the Sociology of Knowledge. London: Penguin Books, 1966. ISBN 0-14-013548-o.

CINGEROVÁ, N. - MOTYKOVÁ, K.: Úvod do diskurznej analýzy. Bratislava: Univerzita Komenského v Bratislave, 2017. ISBN 978-80-223-4385-5.

FOUCAULT, M.: Archeologie vědění. Praha: Hermann \& synové, 2002. ISBN 80-239-0124-9.

FOUCAULT, M.: L'archéologie du savoir. Paris: Gallimard, 1969. ISBN 2-07-026999-X.

GARRET, P. - BELL, A.: Media and Discourse: A Critical Overview. In: BELL, A. - GARRET, P. (eds): Approaches to Media Discourse. Oxford; Malden: Blackwell Publisher, 1998, S. 1-20.

JÄGER, S. - JÄGER, M.: Deutungskämpfe. Theorie und Praxis Kritischer Diskursanalyse. Wiesbaden: VS-Verlag, 2007. ISBN 978-3-531-15072-7.

LACLAU, E.: On Populist Reason. London, New York: Verso, 2007. ISBN 978-18-446-7186-1.

LACLAU, E. - MOUFFE, Ch.: Hegemonie a socialistická strategie: $z$ a radikálně demokratickou politiku. Praha: Karolinum, 2014. ISBN 978-80-246-2685-7.

NIEHR, T.: Einführung in the linguistishe Diskuranalyse. Darmstadt: WBG, 2014. ISBN 978-3-534-25524-5. 
REISIGL, M. - WODAK, R.: Discourse nad Discrimination: Rhetorics of Racism and Antisemitism. London; New York: Routhledge, 2001. ISBN 978-0-41-523150-3.

SPITZMÜLLER, J. - WARNKE, I. H.: Diskurslinguistik. Eine Einführung in Theorien und Methoden der transtextuellen Sprachanalyse. Berlin-Boston: De Gruyter, 2011. ISBN 978-3-11-021244-0.

VAN DIJK, T. A.: Critical Discourse Studies: A Sociognitive Approach. In: WODAK, R. MEYER, M. (eds): Methods of Critical Discourse Analysis. Second Edition. Los Angeles; London; New Delphi; Singapore; Washington DC: Sage Publications, 2010, s. $62-86$.

VAN DIJK, T. A.: Ideology: A Multidisciplinary Approach. London; Thousand Oaks; New Delphi: Sage Publications, 1998. ISBN 0-7619-5655-7.

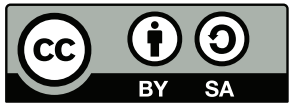

This work can be used in accordance with the Creative Commons BY-SA 4.0 International license terms and conditions (<https://creativecommons.org/licenses/by-sa/4.0/legalcode>). This does not apply to works or elements (such as images or photographs) that are used in the work under a contractual license or exception or limitation to relevant rights.

https://doi.org/10.5817/OS2019-4-10

\section{Život ve slovech, slova v životě}

KLOFEROVÁ, S. - ŠIPKOVÁ, M. (eds): Život ve slovech, slova v životě. Procházka labyrintem českých nářečí. Praha: NLN, 2018. 210 s. ISBN 978-80-7422-657-1.

Stalo se již tradicí, že pracovníci Ústavu pro jazyk český Akademie věd České republiky informují o výsledcích své vědecké práce nejen odborníky, ale i širší veřejnost. Tyto popularizační aktivity se setkávají s velice př́ínivým ohlasem, jak o tom svědčí např. dvoudílný Divnopis, ${ }^{1}$ včetně z něho vycházejících pořadů České televize, ze starších publikací pak třeba Čeština všední $i$ nevšedni $i^{2}$ a mnoho dalších. Tuto řadu nedávno obohatila knížka Život ve slovech, slova $v$ životě s podtitulem Procházka labyrintem českých nářčči, ${ }^{3} \mathrm{v}$ níž prezentují některé výsledky svého bádání

1 JANÁČ, M. - TUMLÍŘ, P. - HARVALÍK, M.: Divnopis: proč se to tak jmenuje? 1. Praha: Radioservis ve spolupráci s Českým rozhlasem, 2006. JANÁČ, M. - TUMLÍ̌̉, P. - HARVALÍK, M.: Divnopis: proč se to tak jmenuje? 2. Praha: Radioservis ve spolupráci s Českým rozhlasem, 2008.

2 KUCHAR̆,J. a kol.: Čeština všední i nevšední: čtvrtý výběr jazykových koutků Čs. rozhlasu $z$ dialektologie, frazeologie a onomastiky. Praha: Academia, 1972.

3 KLOFEROVÁ, S. - ŠIPKOVÁ, M. (eds): Život ve slovech, slova v životě. Procházka labyrintem českých nárečí. Praha: NLN, 2018. 